\title{
A COMPARISON OF GOVERNMENT AND PRIVATE SCHOOLS OF PESHAWAR ON CLASSROOM ENVIRONMENT DIMENSIONS
}

\author{
Lubna Nazneen* \& Summiya Ahmad $\dagger$
}

\begin{abstract}
Present research was a comparative study of government and private schools of Peshawar on psychosocial aspects of classroom environment. Data was collected from250 subjectsincluding136 boys and 114 girls, having age range of 13-14 years. A cross sectional survey research design was used. Sample was chosen from two private and two government schools of Peshawar, using cluster sampling technique. The classroom environment questionnaire, What Is Happening In This Class? (Fraser, McRobbie \& Fisher, 1996) was administered to collect data from the subjects. Significant differences were observed between government and private schools of Peshawar on psychosocial, classroom environment dimensions of Investigation, task orientation and level of cooperation among students. Government school students showed gender differences in the areas of teacher's support and cooperation whereas private schools showed gender differences in the areas of students' cohesiveness, Involvement in classroom activities, investigation, task orientation and equity.
\end{abstract}

Keywords: Psychosocial classroom environment, government, private, school

\section{Introduction}

A physical, psychosocial, and educational setting in which learning takes place and hence increases student success and positive attitude towards studies is known as learning environment. There is no doubt that education is a very important part of our life. Children spent most of their days' time at

\footnotetext{
Department of psychology Islamia College Peshawar; PhD Scholar Department of Psychology University of Peshawar.

$\dagger$ Associate Professor Department of Psychology University of Peshawar.
} 
school. Classroom environment plays important role in increasing student's interest in studies and improving their academic achievement (Fraser, 2007, 2012) Present day education system emphasizes effective learning in the classroom setting (Waseer, 2008).It is a major concern of the parents to admit their children in the school with an excellent learning environment, which may lead to their better adjustment and academic achievement.

Kyriakides (2006) discovered relationship between teacher student interface and effective learning for the students of grade $12^{\text {th }}$ in Cyprus. Other such studies examined the effect of school environments on student results in mathematics (Webster \& Fisher, 2004). Classroom environment was found to have a positive correlation with achievement and attitudes in the science class at middle school level (Wolf \& Fraser, 2008). Considering the past studies now it is clear that we need to develop new ways and identify important classroom environment variables which can play significant role in better academic outcomes (Candeias \& Rebelo, 2010).

It is a common observation in Pakistan that people tend to admit their children in private rather than government schools because they are considered as having a better environment and more learning opportunities for students. Many research studies focused on the comparison of different characteristics of the school systems all over the world. National Assessment of Educational Progress (NAEP) reported results regarding students' knowledge innumerous domains. It was found that private schools had better results in most of the subjects including mathematics and science as compared to public schools (U.S. Department of Education 2012). By analyzing the data NAEP 2003, National Center for Education Statistics (NCES) showed astonishing proofs regarding better performance of public school as compared to private school students.

Most of the private schools are English medium and the teachers employed there are also very much qualified and trained. Similarly, other facilities in the classrooms of private schools are also superior to the government schools, for example sophisticated materials for different creative activities. Experience with advance equipment in English medium schools enhance' students' skills and their level of achievement (Shabbir et al., 2014). In another study significant differences were found in the achievement of government and private school (Siddiqui \& Gorard, 2017).

Present study has a focus on finding out the differences in the psychosocial classroom environment of government and private schools with reference to some important classroom environment dimensions. Students' attachment level with their school and interest in studies is dependent upon the activities they engage in, at school and on the level of participation of their family in the school decision making process (Abreu, Veiga, Antunes \& Ferreira, 2006). Past studies proved that students' learning is highly influenced by their learning environment (Fraser, 1999).

Quality human capitals are generated through better education in a country. Justifiable financial progress of a country also requires skillful people, and all these skills are acquired through education (Nasir \& Nazli, 2010). The major obstacle in the path of financial growth is illiteracy. 
Nowadays a big \% of students are enrolled in private schools, and this tendency has increased to such an extent that even the poorest families incline to send their students to private schools. This research was conducted to know about the facts behind such attitudes of parents and to focus on the main differences between the classroom environments of public and private schools. As it is already proved by other research that private schools are performing better, this study will focus on those dimensions which might be creating these differences.

\section{Psychosocial Classroom Environment Dimensions}

Student Cohesiveness: Level of friendliness and support between the students.

Teacher Support: Helping behavior and support shown by the teacher.

Involvement:

Attention and participation in classroom activities, including discussion with other students in the understanding and applicability of new ideas.

Investigation: $\quad$ Use of skills in the solution of problems and ability to investigate.

Task Orientation: Giving importance to the completion of already decided activities and keeping a focus on the activity.

Cooperation: level of cooperation between the students in the classroom.

Equity: Level of equality in giving appreciation, asking questions and providing a chance to be included in classroom discussion to the students by the teacher.

\section{Objectives}

- To compare the classroom environments of government and private schools with reference to different classroom environment dimensions.

- To study gender differences on different classroom environment dimensions in Government and private schools.

\section{Hypothesis}

- There will be significant differences in psychosocial classroom environments of Government and private schools in Peshawar.

- Significant differences will be seen between girls and boys on classroom environment dimensions in Government and private schools.

\section{Methodology}

Research Design: A Cross sectional survey research design was used to conduct the study. 
Sample: A sample of 250 students with age range 13-14 years were selected from two government and two private schools of Peshawar using convenience sampling method.71 male and 37 female students from private schools and 65 males and 77 females of class $7^{\text {th }}$ and $8^{\text {th }}$ from government schools participated in the study.

Instrument: A 56 items questionnaire What Is Happening In this Class? (WIHC) (Fraser, McRobbie \& Fisher, 1996) was used in this study. The questionnaire was in English and it consisted of seven scales. Every scale had 8 items. Being a highly reliable and valid scale, it was used for data collection on similar topics throughout the world (Dorman, 2008). A fivepoint likert scale was used in the questionnaire. Its seven subscales were student cohesiveness, teacher support, involvement, task orientation, investigation, cooperation, and equity. Five-point likert scale was used for quantifying responses on each item.

Procedure: After taking permission from the principals of the selected schools, students' consent was taken for participation in the study. Students were also briefed regarding the purpose of the study. Responses were obtained from students age 13-14 on a 56-item questionnaire "What Is Happening In This Class?” (WIHIC) (Fraser, McRobbie \& Fisher, 1996). Convenience sampling method was used to select these subjects and group administration of the questionnaire was done to collect data from them. Students took a great interest in the study and they showed their maximum cooperation.

\section{Results}

Table 1: Demographic Profile of Participants in the Study $(\mathrm{N}=250)$

\begin{tabular}{|c|c|c|c|c|}
\hline & Age (13-14) & $\begin{array}{c}\begin{array}{c}\text { Socio } \\
\text { economic } \\
\text { status }\end{array} \\
\end{array}$ & No of siblings & Parental occupation \\
\hline $\begin{array}{l}\text { Govt } \\
\text { schools } \\
(\mathrm{n}=108)\end{array}$ & $\begin{array}{l}\text { Age } 13=50 \\
\text { Age } 14=58\end{array}$ & $\begin{array}{l}80=\text { middle } \\
\text { class } \\
28=\text { lower } \\
\text { class }\end{array}$ & $\begin{array}{l}40=6 \text { sibling } \\
35=5 \text { siblings } \\
30=4 \text { siblings } \\
3=1 \text { sibling }\end{array}$ & $\begin{array}{l}80=\text { Government } \\
\text { servants in } \\
\text { different fields } \\
28=\text { doing small } \\
\text { business and labourers }\end{array}$ \\
\hline $\begin{array}{l}\text { Private } \\
\text { schools } \\
(\mathrm{n}=142)\end{array}$ & $\begin{array}{l}\text { Age } 13=70 \\
\text { Age } 14=72\end{array}$ & $\begin{array}{l}60=\text { Middle } \\
\text { class } \\
82=\text { Upper } \\
\text { class }\end{array}$ & $\begin{array}{l}30=5 \text { siblings } \\
45=4 \text { siblings } \\
20=3 \text { siblings } \\
40=2 \text { siblings } \\
7=\text { single child }\end{array}$ & $\begin{array}{l}60=\text { Government } \\
\text { servants. } \\
82=\text { doing some good } \\
\text { business and having } \\
\text { high profile jobs. }\end{array}$ \\
\hline
\end{tabular}


Table 2: Psychometric Properties of Scales in the Study (N=250)

\begin{tabular}{cccccccc}
\hline Scale & $\begin{array}{c}\text { No of } \\
\text { items }\end{array}$ & Mean & SD & $\boldsymbol{\alpha}$ & Potential & actual & Skew \\
\hline WHICH & 56 & 188.87 & 31.98 & .92 & $56-280$ & $75-270$ & -.19 \\
\hline
\end{tabular}

Table 3: Mean Difference, SD, t-value of Government and Private School Students on different dimensions of Classroom Environment scale $(\mathbf{N}=\mathbf{2 5 0})$

\begin{tabular}{|c|c|c|c|c|c|c|c|c|}
\hline \multirow{3}{*}{$\begin{array}{l}\text { WIHIC } \\
\text { Scales }\end{array}$} & \multirow{2}{*}{\multicolumn{2}{|c|}{$\begin{array}{c}\text { Govt schools } \\
(n=108)\end{array}$}} & \multirow{2}{*}{\multicolumn{2}{|c|}{$\begin{array}{c}\text { Private schools } \\
(n=142)\end{array}$}} & \multirow{3}{*}{$\mathrm{t}(248)$} & \multirow{3}{*}{ p } & \multicolumn{2}{|c|}{ CI $(95 \%)$} \\
\hline & & & & & & & LL & UL \\
\hline & M & SD & $\mathrm{M}$ & SD & & & & \\
\hline Stud coh & 29.79 & 6.21 & 27.61 & 7.12 & 2.53 & .012 & 0.48 & 3.87 \\
\hline Teach & 27.74 & 7.78 & 26.32 & 5.32 & 1.70 & .08 & -0.21 & 3.05 \\
\hline Involvement & 25.09 & 7.50 & 26.72 & 5.10 & -2.0 & .042 & -3.20 & -0.06 \\
\hline Investigation & 19.75 & 6.66 & 22 . & 6.19 & -2 & .005 & -3.89 & -0.68 \\
\hline & 35.52 & 6.2 & 26. & 6.87 & 10.2 & .000 & 6.96 & 10.27 \\
\hline & 29.90 & 10. & & 5.6 & 3. & .000 & 1.88 & 5.99 \\
\hline Equity & 29.81 & 7.27 & 28.27 & 6.36 & 1.78 & .076 & -0.16 & 3.24 \\
\hline
\end{tabular}

Note: Student coh: students' cohesiveness. Teacher sup: Teacher's support, Task orient: Task orientation.

Table 3 shows mean differences between Government and private schools on different classroom environment dimensions .significant differences can be seen on task orientation, cooperation between students, investigation, students' cohesiveness and students' involvement dimensions.

Table 4: Mean Difference, SD, $t$-value of Male and Female Students of Government and Private Schools on different dimensions of Class room Environment scale $(\mathbf{N}=\mathbf{2 5 0})$

\begin{tabular}{lccccccc}
\hline $\begin{array}{l}\text { WHICH } \\
\text { Scales }\end{array}$ & \multicolumn{2}{c}{$\begin{array}{c}\text { Boys } \\
(\mathrm{n}=136)\end{array}$} & \multicolumn{2}{c}{$\begin{array}{c}\text { Girls } \\
(\mathrm{n}=114)\end{array}$} & $\mathrm{t}(248)$ & \multicolumn{2}{c}{$\mathrm{CI}(95 \%)$} \\
\cline { 2 - 9 } & $\mathrm{M}$ & $\mathrm{SD}$ & $\mathrm{M}$ & $\mathrm{SD}$ & & $\mathrm{LL}$ & $\mathrm{UL}$ \\
\hline Govt School & & & & & & & \\
Student coh & 28.98 & 6.54 & 31.35 & 5.46 & -1.90 & .060 & 0.10 \\
Teacher supp & 29.92 & 8.03 & 23.54 & 5.17 & 4.38 & .000 & 9.28 \\
Involvement & 24.45 & 7.76 & 26.32 & 6.92 & -1.23 & .220 & 1.13 \\
Investigation & 19.25 & 6.19 & 20.72 & 7.48 & -1.09 & .227 & 1.20 \\
Task orient & 36.43 & 4.08 & 33.78 & 8.78 & 2.14 & .034 & 5.10 \\
cooperation & 26.36 & 6.49 & 36.70 & 13.43 & -5.39 & .000 & -6.54 \\
Equity & 30.54 & 7.63 & 28.40 & 6.39 & 1.46 & .126 & 5.05 \\
\hline
\end{tabular}




\begin{tabular}{lccccccc}
\hline Private School & & & & & & & \\
Student coh & 30.23 & 5.84 & 25.40 & 7.38 & 4.26 & .000 & 7.06 \\
Teacher supp & 27.32 & 3.85 & 25.48 & 6.34 & 2.07 & .039 & 3.59 \\
Involvement & 28.63 & 3.94 & 25.11 & 5.42 & 4.34 & .000 & 5.11 \\
Investigation & 20.58 & 6.58 & 23.28 & 5.82 & -2.64 & .009 & -0.68 \\
Task orient & 29.26 & 5.10 & 24.92 & 7.54 & 3.93 & .000 & 6.51 \\
cooperation & 27.12 & 4.45 & 24.98 & 6.34 & 2.27 & .024 & 3.98 \\
Equity & 31.49 & 3.66 & 25.55 & 6.89 & 6.23 & .000 & 7.81 \\
\hline
\end{tabular}

Note: Student coh: students' cohesiveness. Teacher sup: Teacher's support, Task orient: Task orientation.

Table 4 shows mean differences between girls and boys of Government and private schools. There are significant differences at $<.001$ on teacher's support and cooperation among students for government school students. Similarly for private school students highly significant differences are found at <.001 between boys and girls on students' cohesiveness, students' Involvement in classroom activities, investigation, task orientation and equity whereas slightly significant differences at $<.05$ are observed on teacher's support and cooperation among students of a class.

\section{Findings and Discussion}

Purpose of this research was to study differences along different classroom environment dimensions between the government and private schools. Mean differences between government and private schools on classroom environment dimensions showed that Government schools were high on students' cohesiveness, task orientation and cooperation in their classroom environment, whereas private schools were high on level of investigation by their students and students' involvement dimensions. Hoffner-Moss and Fraser (2002) found that providing excellent classroom environment to the students, they would show more involvement leading towards better learning. Most of the research studies reported that English medium schools have better technical facilities including computer, multimedia and access to digital libraries as compared to Urdu medium schools (Dogar, Butt, Butt \& Qaisar, 2015; Khurshid, Shah \& Reid, 2016; Siddiqui \& Gorard, 2017). Marjori banks, (2004) found relationship between learning contexts, family environments, instructional objectives, and educational achievement. Comparison across gender showed that significantly higher levels of teacher's support and task orientation was found in boys and significantly higher levels of cooperation was seen in girls of Government schools. Students' cohesiveness, students' involvement in classroom activities, investigation, task orientation and equity were significantly higher in boys of private schools as compared to girls. Wright (2003) discovered that male students less frequently, ask their teachers for help, might be because of some social pressures. But at the same time, they 
are also found to be involved in different research activities together with their colleagues (Drew \& Work, 1998). These characteristics of boys can be seen even in their earlier grades (Fennema, et al., 1998).

\section{Summary and Conclusion}

Current research was intended to make a comparison of the government and private schools on multiple classroom environment dimensions. A sample of 250 subjects' including 136 boys and 114 girls was selected from two government and private schools using convenient sampling technique. They were middle school students between 13 and 14 years of age. A 56item questionnaire "What Is Happening In This Class? (WIHIC)" (Fraser, McRobbie \& Fisher, 1996) was used. Significant differences were observed in the classroom environments of government and private schools on various dimensions of classroom environment. There were also significant gender differences on different classroom environment aspects in government and private schools. It is concluded that government schools are better places for learning cohesiveness, task orientation and cooperation, but level of investigation and involvement in classroom activities was better in private school students. This is the reason that private school students have better learning and are more creative.

\section{Limitations of the Study}

An important limitation of this study was the use of a lengthy scale which took much time in completion by the students. In the beginning they took much interest but when reaching to the end they were feeling tired. As present study was focused only on doing a comparison of psychosocial classroom environment by taking only a small cross section of the population, in the form of two government and two private schools.

\section{Recommendations}

Government schools should increase the level of democracy in their classroom environments, to enhance student's level of involvement in classroom activities and investigation about different concepts. More diverse studies are needed in the same area by doing proper randomization and increasing the size of the sample as well. Moreover, classroom environment as a determinant of student's achievement level and personality should also be studied. Physical environment of the classroom and student's level of intrinsic motivation for studies should also be studied in detail. As per the results of present study. 


\section{References}

Abreu, M., Veiga, F.H., Antunes, J., \& Ferreira, A. (2006). Attitudes towards the school and self-interest in students from different family contexts. In Tavares (chair),

Activation of Psychological Development [Symposium]. 30 ${ }^{\text {th }}$ annual convention Aveiro.

Candeias, A.A. \& Rebelo, N. (2010). Student' Attitudes toward School, Learning, Competence and Motivation - the effects of gender, contextual background, school failure and development. School Cohabitation Research. 5, 547-55.

Dorman, J.P. (2003). Cross-national validation of the What Is Happening In this Class? (WIHIC questionnaire using confirmatory factor analysis. Learning Environments Research, 6, 231-245.

Drew, T.L., \& Work, G.G. (1998). Gender-based differences in higher education: Gaining a broader perspective. Journal of Higher Education, 69(5), 542-555.

Fennema, E., Carpenter, T.P., Jacobs, V.R., Franke, M.L. \& Levi, L.W. (1998). A longitudinal study of gender differences in young children's mathematical thinking. Educational Researcher, 27, 6-11.

Fraser, B.J., Fisher, D.L. \& McRobbie, C.J. (1996, April 8-12). Development, validation, and use of Personal and class forms of a new classroom environment instrument [Paper presentation]. $70^{\text {th }}$ annual meeting of the American Educational Research Association, New York.

Fraser, B.J. (2007). Classroom learning environments. In S. K. Abell and N. G. Lederman (Eds.), Handbook of research on science education $\left(2^{\text {nd }}\right.$ ed., pp. 190-220). Lawrence Erlbaum.

Fraser, B.J. (2012). Classroom learning environments: Retrospect, context, and prospect. In B.J. Fraser, K.G. Tobin \& C.J. McRobbie (Eds.), Second international handbook of science Education (pp.100-122). Springer.

Hoffner-Moss, M.C. \& Fraser, B.J. (2002, June 5-10). Using environment assessments in improving teaching and learning in high school biology classrooms. [Paper presentation]. $24^{\text {th }}$ annual meeting for the National Assessment of Educational Progress, New Orleans.

Kyriakides, L. (2006). Measuring the learning environment of the classroom and its effect on cognitive and affective outcomes of schooling. In D.L. Fisher \& M.S. Khine (Eds.), Contemporary approaches to research on learning environments (pp. 97-115).World Views.

Marjori banks, K. (2004). Learning environments, family contexts, educational aspirations and attainment: A moderation-mediation model extended. Learning Environments Research, 6, 247-265.

Nasir \& Nazli (2010). "Education and Earnings In Pakistan", Working Papers \& Research Reports, 1991, 1-25. 
Shabbir, Muhammad. (2014). A Comparative Study of Public versus Private Primary Schools, An Evidence from Azad Kashmir, Journal of Education and Practice. 5, 164-168.

Siddiqui, N., \& Gorard, S. (2017). Comparing government and private schools in Pakistan: The way forward for universal education. International Journal of Educational Research, 82, 159-169. https://doi.org/10.1016/j.ijer.2017.01.007

U.S. Department of Education (2012). Student Achievement In Private Schools, National Assessment to Educational Progress, National center for Education Statistics (2006) https://nces.ed.gov/nationsreportcard.pdf

Waseer, M.J. (2008). Effects of class room Physical Environment on the Academic Achievement of Students in Subject of English at Elementary School Level [Unpublished MPhil Thesis] Allama Iqbal Open University, Islamabad.

Webster, B.J., \& Fisher, D.L. (2004). School-level environment and student outcomes in Mathematics. Learning Environments Research, 6, 309326.

Wolf, S.J., \& Fraser, B.J. (2008). Learning environment, attitudes and achievement among middle school science students using inquiry-based laboratory activities. Research in Science Education, 38, 321-341.

Wright, R.R. (2003). Real men don't ask for directions: Male student attitudes toward peer tutoring. Journal of College Reading and Learning, 34(1), 61-75. 